\title{
Analysis of climate hazards in relation to urban designing in Iran
}

\author{
S. Alijani ${ }^{1}$ and B. Alijani ${ }^{2}$ \\ ${ }^{1}$ Department of Urban Designing, Islamic Azad University, Tehran, Iran \\ ${ }^{2}$ Center of Excellence for Spatial Analysis of Environmental Hazards, Tarbiat Moallem University, Tehran, Iran
}

Received: 19 January 2011 - Revised: 5 April 2011 - Accepted: 15 May 2011 - Published: 14 June 2011

\begin{abstract}
In order to study the climate hazards, daily rainfall and temperature data of 61 weather stations over the country were obtained from the Meteorological Organization of Iran for the 1951-2007 period. The following indices are defined as indications of climate hazards: sultriness of the air or the heat index, cold days with minimum temperature below $-5^{\circ} \mathrm{C}$, warm days with maximum temperature above $32^{\circ} \mathrm{C}$, the share of extreme rain days from the annual rainfall. The annual frequencies of these indices are analyzed and the overall hazard index is computed using the Analytical Hierarchical Process method.

The results show that the southern coastal areas and central deserts are the most hazardous parts of the country, whereas, the northern Caspian coastal lands and mountainous regions experience lower hazard alerts. The problem of the northern parts is the cold days and that of the southern areas is the hot and humid days. Despite the relatively equal occurrence of torrential rains over the country, they are more harmful in the south than in the other parts of the country.
\end{abstract}

\section{Introduction}

Phenomena like flash floods or heat waves and their possible erratic occurrence are important climate hazards (Alijani et al., 2008) for designing and planning the urban centers, predominantly in arid regions of the globe. The impact of these climate hazards is serious and destructive in the dense and fragile populated settlements. They usually damage the urban infrastructures; create polluted environment, and unhealthy living conditions. The degree of damage (climate risk) of these hazards depends among other factors such as vulnerability and exposure of the environment, on their extent, severity, and especially their probability of occurrence (Gwilliam et al., 2006).

The concern about the impact of the physical environment on the urban development can be traced more than 2000 years back to the time of Vitruvius who has discussed in his book "The Ten Books on Architecture" the importance of climate on the layout of cities (Morgan, 1960). Since then many publications have focused on the climate impact of the city. Grunthal and his colleagues (2006) have analyzed the damage of three main hazards in the city of Cologne, Germany

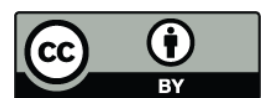

Correspondence to: B. Alijani

(alijani@tmu.ac.ir) and present the suitable methods to analyze their impact. The works of Olgyay (1963) and Givoni (1998) have presented good tools for measuring human comfort indices in the urban areas. Scientists of some institutions such as the Meteorological Institute of the University of Freiburg, Germany have done remarkable researches in the area of climate and human health. Works of A. Matzarakis (such as Matzarakis and Mayer, 2000) are good examples of this kind. For more information about the interaction between city and the environment the readers are referred to works of Oke (e.g., Oke, 1987).

During the past one hundred years the global temperature has increased about $0.74{ }^{\circ} \mathrm{C}$ (IPCC, 2007; Zhang et al., 2005). In Iran, the outcome of this global warming is the increasing frequency of extreme events such as cold spells, heat waves, torrential rains, or prolonged intensive droughts (Rahimzadeh et al., 2009); hence increasing danger and harm to the built environments and people. The analysis of intensity and frequency of these extreme events is a very important step in the process of planning and designing the urban areas especially in the semi arid climate of Iran. In these areas climate is very fragile and a sudden change may cause destructive outcomes. During the 2000-2008 period droughts and floods were the first in terms of economic loss and number of affected people in Iran (http://www.emdat.be/search-details-disaster-list). 
Table 1. Indices used to identify extreme climatic events.

\begin{tabular}{ll}
\hline Heat Index (HI) & ET $=-42.379+2.04901523 \mathrm{~T}+10.14333127 \mathrm{R}-0.22475541 \mathrm{TR}-6.83783 \times 10^{3} \mathrm{~T}^{2}-$ \\
& $5.481717 \times 10^{2} \mathrm{R}^{2}+1.22874 \times 10^{3} \mathrm{~T}^{2} \mathrm{R}+8.5282 \times 10^{4} \mathrm{TR}^{2}-1.99 \times 10^{6} \mathrm{~T}^{2} \mathrm{R}^{2}$ \\
Cold Days (CD) & Days with minimum temperature below $-5{ }^{\circ} \mathrm{C}$ \\
Warm Days (WD) & Days with maximum temperature above $32^{\circ} \mathrm{C}$ \\
Extreme Rains Percentage (ERP) & Ratio of extreme rains from the annual rain \\
\hline
\end{tabular}

The spatial and temporal variability is the intrinsic characteristic of the climate of Iran. According to Tagavi and Mohammadi (2007) during the past years, the frequency of cold events has decreased while that of warm events has increased. Kary (2010) has confirmed the significant change of the heat waves and cold spells in Tehran during past years. All these studies and others such as the work of Rasooli (2004) about the spatial analysis of cold winds over the northwestern Iran and that of Kaviani and his colleagues (2004) about the effective temperature over the country show the variability and uncertainty of the climate over the country. Therefore it is very important for the planners, designers, and managers of the urban environments to pay attention to the climatic considerations. In any part of the country its especial climate should be understood and the extreme cases ought to be analyzed. But up to now no comprehensive work has been carried out in this field; the task which this research has undertaken. The following section is devoted to the description of data and methodology. The main outcome of this investigation is presented in the Results section. The paper is closed with a brief conclusion.

\section{Data and methodology}

A great deal of literature has been carried out about the definition and impacts of the climate hazards on the environment and people. The thresholds are defined differently. Some researchers use the percentile thresholds such as the above 90th percentile or the below 5th percentile (Hayhoe et al., 2004; Díaz et al., 2006). While the others may use absolute values such as $32{ }^{\circ} \mathrm{C}$ or daily rains above $30 \mathrm{~mm}$. Most researchers use both methods (Bell et al., 2004; Frich et al., 2002; Haylock and Nicholis, 2000; Bärring and Persson, 2006). Considering all these different methods the following four indices (Table 1) are defined in this study.

The first index in Table 1 is a combination of temperature ( $T$, in degrees Fahrenheit) and relative humidity (RH, in decimal format) called Heat Index (HI). It is defined as the overall effect of the combination of temperature and relative humidity (Steadman, 1979). For, most of the time the atmosphere is calm in the urban environment and the amount of the relative humidity controls the effect of the temperature. The higher relative humidity increases the adverse effect of the temperature (Zaboli, 2010). We use this index to mea-

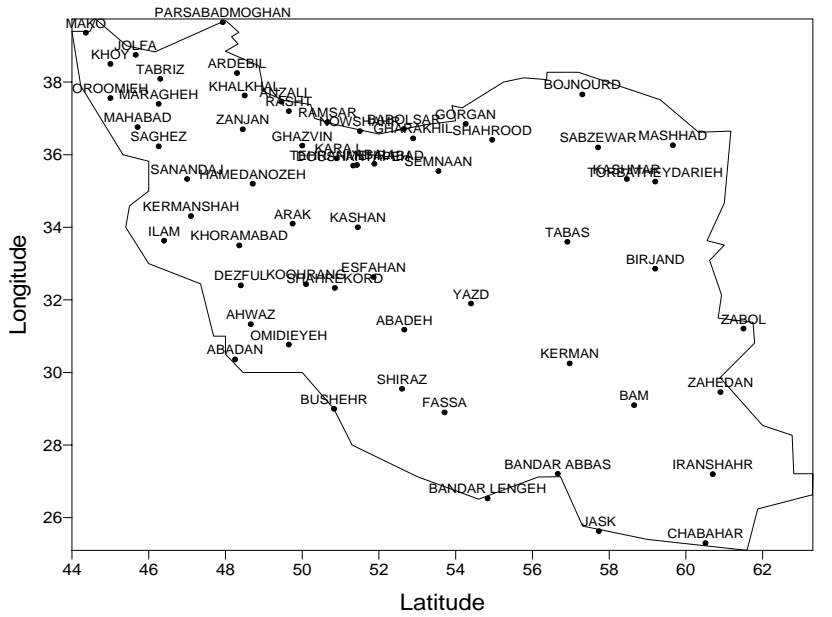

Figure 1. The location of the study stations.

sure the heat stress on humans. Days with HI value above 80 are considered the days with heat stress causing adverse impacts such as sunstroke, muscle cramps and other related problems. These values are averaged on the annual basis for each station. The days with a minimum temperature below $-5^{\circ} \mathrm{C}$ are defined as days with cold stress, because in the dry environment of Iran the temperatures above $-5^{\circ} \mathrm{C}$ are more common and the environment is adopted to it. In the same way the warm days are defined as days with maximum temperature above $32^{\circ} \mathrm{C}$. The ratio of the rainfall of extreme daily rains from the annual rainfall is defined as the Extreme Rains Percentage (ERP). A day with extreme rainfall is defined as a day with rainfall above the 90th percentile of the station daily rainfall time series during the study period; dry days are not included in this time series. The defined indices are extracted from the daily data of 61 synoptic stations during the period starting from 1951 to 1985 and ending to 2007. The studied stations were shown in Fig. 1.

The overall hazardiness of each station is calculated according to the Analytical Hierarchical Processing (AHP) method, developed by Saati (Saati, 1980). In this method each of the four indices is weighted according to its importance. The HI is considered as the most important index for humans. The ERP index is defined as the second important index in the urban planning and designing, because, the extreme rains usually far exceed the capacity of cities 
Table 2. Weighting of indices.

\begin{tabular}{lcccccc}
\hline & HI & ERP & CD & WD & Weights & $\begin{array}{c}\text { Normalized } \\
\text { Weights }\end{array}$ \\
\hline HI & 1 & 3 & 5 & 7 & 3.20 & 0.56 \\
ERP & 0.33 & 1 & 3 & 5 & 1.49 & 0.26 \\
CD & 0.2 & 0.33 & 1 & 3 & 0.67 & 0.12 \\
WD & 0.1429 & 0.2 & 0.33 & 1 & 0.31 & 0.05 \\
& & & & & 5.67 & 1 \\
\hline
\end{tabular}

Table 3. Weighting of four classes of Heat Index.

\begin{tabular}{lcccccc}
\hline & $201-262$ & $139-200$ & $76-138$ & $13-75$ & Weights & $\begin{array}{c}\text { Normalized } \\
\text { Weights }\end{array}$ \\
\hline $201-262$ & 1 & 3 & 5 & 7 & 3.20 & 0.56 \\
$139-200$ & 0.33 & 1 & 3 & 5 & 1.49 & 0.26 \\
$76-138$ & 0.2 & 0.33 & 1 & 3 & 0.67 & 0.12 \\
$13-75$ & 0.1429 & 0.2 & 0.33 & 1 & 0.31 & 0.05 \\
& & & & & 5.67 & 1
\end{tabular}

and cause destructive floods and damage buildings and other infrastructures. Their destructive effect is manifold in dry environments such as Iran due to their rare and erratic occurrence. The frequency of cold spells comes as the third important index in urban planning and designing. Colder and biter temperatures are very harmful for people and infrastructures, especially in the arid climate of Iran. The Warm Days are scored as the least important of all, because, high temperatures are very frequent in arid areas and people and structures are adopted to them. The pair wise preferences of e.g. the indices are defined from 7 for HI to 1 for WD (Saati, 1980) and shown in Table 2. According to this table, the preference of $\mathrm{HI}$ is seven times WD, the preference of ERP is 3 times $\mathrm{CD}$ and 5 times WD. In each row the preference scores are geometrically averaged and written in the Weights column. The normalized weights are shown in the final column. This column indicates that the importance of $\mathrm{HI}$ in causing hazard for the environment is 5.5 times $\mathrm{CD}(0.56 / 0.12=5.5)$. Each index is divided into four subgroups and processed according to the same method described in Table 2; subgroups of $\mathrm{HI}$ are shown as an example in Table 3.

Each index is divided into four classes and weighted according to their frequency during the study period (Table 4).

The final preference scores are computed by multiplying the normalized weights of the indices and their subgroups (Table 4). The scores of the final column of Table 4 are given to the related value of each index in the actual data table as exemplified in Table 5.

The hazard score of each station (last column of Table 5) is added up from the weights given to the values of the indices in that station according to Table 4. The spatial distribution of hazard indices is interpolated and drawn with the Inverse Distance Weight method.
Table 4. The final scores used for classifying indices.

\begin{tabular}{lcccc}
\hline First Level & Score & Second Level & Score & Final Score \\
\hline HI & 0.56387 & $201-262$ & 0.564428 & 0.318 \\
HI & 0.56387 & $139-200$ & 0.263004 & 0.148 \\
HI & 0.56387 & $76-138$ & 0.117619 & 0.066 \\
HI & 0.56387 & $13-75$ & 0.054948 & 0.031 \\
ERP & 0.263004 & $0.494-0.549$ & 0.564428 & 0.148 \\
ERP & 0.263004 & $0.438-0.493$ & 0.263004 & 0.069 \\
ERP & 0.263004 & $0.382-0.437$ & 0.117619 & 0.031 \\
ERP & 0.263004 & $0.326-0.381$ & 0.054948 & 0.014 \\
CD & 0.117619 & $84-109$ & 0.564428 & 0.066 \\
CD & 0.117619 & $56-83$ & 0.263004 & 0.031 \\
CD & 0.117619 & $28-55$ & 0.117619 & 0.014 \\
CD & 0.117619 & $0-27$ & 0.054948 & 0.006 \\
WD & 0.054948 & $309-411$ & 0.564428 & 0.031 \\
WD & 0.054948 & $206-308$ & 0.263004 & 0.014 \\
WD & 0.054948 & $103-205$ & 0.117619 & 0.006 \\
WD & 0.054948 & $1-102$ & 0.054948 & 0.003 \\
\hline
\end{tabular}

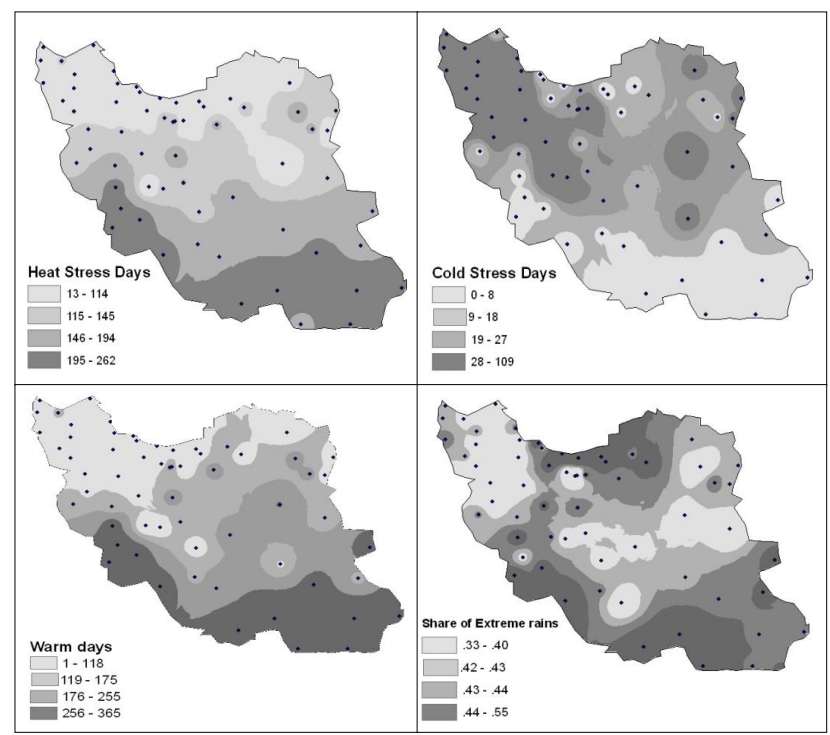

Figure 2. Spatial distribution of hazard indices.

\section{Results}

The spatial distributions of the selected indices are shown in Fig. 2. The spatial distributions of all maps are divided into four quintiles. According to the HI map, the frequency of these days is high in the south and decreases toward the north. The southern parts of the country suffer from sultry weather. The sultry conditions develop harm to human body and cause susceptible environment for different diseases. Therefore it is a severe limitation for the urban development and expansion. The same spatial pattern exists in the warm days map. It is obvious from these two maps that the southern quarter of the country needs more energy to mitigate this hot and humid environment. 
Table 5. An example of weighting of each station.

\begin{tabular}{|c|c|c|c|c|c|c|c|c|c|}
\hline \multirow[t]{2}{*}{ Station } & \multicolumn{4}{|c|}{ Values } & \multicolumn{4}{|c|}{ Weights } & \multirow[t]{2}{*}{ Hazard Score } \\
\hline & HI & $\mathrm{CD}$ & WD & ERP & Hid & ERP & $\mathrm{CD}$ & WD & \\
\hline ABADAN & 224 & 0 & 360 & 0.46 & 0.32 & 0.069 & 0.006 & 0.031 & 0.426 \\
\hline ABADEH & 126 & 26 & 75 & 0.41 & 0.07 & 0.031 & 0.006 & 0.003 & 0.11 \\
\hline ABALI & 13 & 109 & 1 & 0.45 & 0.03 & 0.069 & 0.066 & 0.003 & 0.168 \\
\hline AHWAZ & 221 & 0 & 361 & 0.41 & 0.32 & 0.031 & 0.006 & 0.031 & 0.388 \\
\hline
\end{tabular}

The spatial distribution of cold days is in contrast with that of the warm or sultry days. On this map the northwestern parts and the central Zagros are suffering from cold weather. Here also, more energy is required to compensate this cold environment. According to these maps of warm and cold days both the southern and northern parts of the country need more energy to provide a suitable environment for urban dwellers throughout the year. The share of the torrential rains from the annual rainfall varies from 33 to $55 \%$ over the country. Thus all of the country is vulnerable for torrential rains with some emphasize to the coastal lands. Urban floods are severe and frequent in the coastal areas, especially in the very dry and erratic climate of the South.

The comparison of these four maps indicates that at any place in the country there exists at least one climatic problem for urban activities. But places such as the southern coastal lands experience multiple hazards of hot and sultry climate together with torrential rains. These climate hazards are seasonal in most of the country, but dominate all year around in the southern coastal areas.

\section{Hazard map}

The computed susceptibility or vulnerability to the climate hazards of each station as exemplified in Table 5, are given in Table 6 and drawn in Fig. 3. According to this figure the most vulnerable places of the country are the southern coastal areas. Here most of the year the hot and humid climate is dominant. The daily rainfall is very erratic and torrential. The region suffers most of the year from either torrential rains or very serious droughts. The colder areas of the north and mountains and drier central parts of the country do not exhibit a harsh environment. The vulnerability of these parts is about one third of the southern regions $(0.18 / 0.56=0.33)$. The comparison of the ERP map of Fig. 2 with the hazard map of Fig. 3 shows that the relatively higher percentage of torrential rains in the southern coasts of the Caspian Sea does not lead to the hazardous conditions, because, these heavy rains are more common in the Caspian coast and the region is adopted to them. But due to their erratic and infrequent occurrence, the torrential rains always cause serious problems in the South.

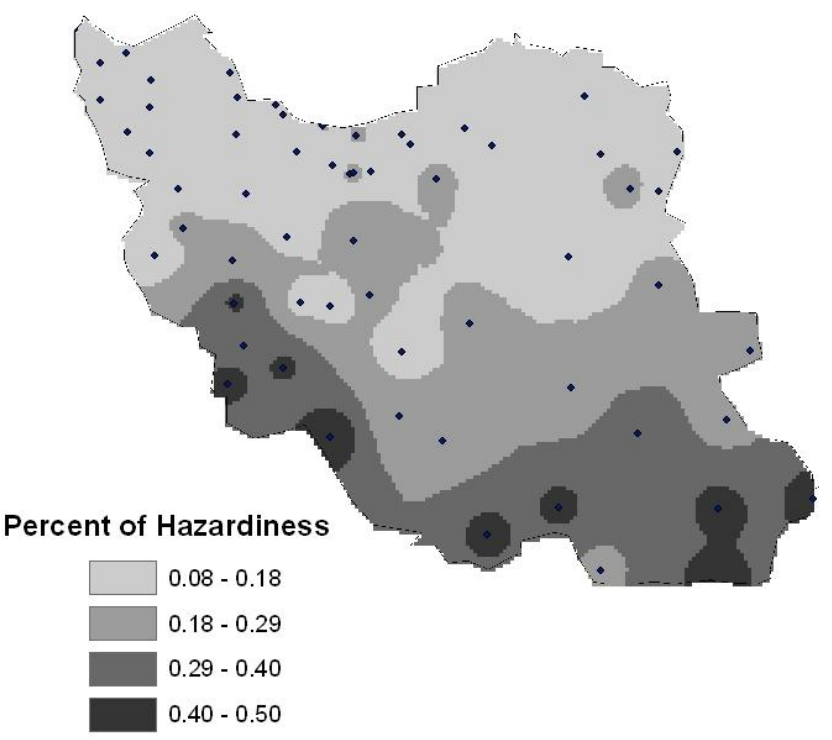

Figure 3. Spatial variation of climate hazard in Iran.

An important point to be mentioned is that our measure of climatic vulnerability is based on the annual frequency of the extreme climatic conditions. Because, the persistence of hazardous conditions cause more problem than their intensity. The prolonged cold weather of winter 2006 caused very high damage over the country or the persisting snow storm of Gilan Province in winter 2005 damaged most of the urban structures of the area. As a result, the southern regions with frequent extreme climate conditions show up as hazardous parts of the country; the fact that exists in reality. In the northern parts of the country, the severe cold conditions or harmful sultry conditions do not persist for long periods. In these areas, due to the dominance of westerlies during the cold season, the hazardous cold conditions last short times of maybe 5 to 7 days (Alijani, 2002), after which a sunny weather warms the environment and lowers the degree of vulnerability.

The hazard map indicates that there is climatic vulnerability for urban centers all over the country. The urban managers and planners or designers should take into consideration the cold weather problems such as street frosts and snow accumulation, winter season energy consumption in the 
Table 6. The climatic hazard score of the studied stations.

\begin{tabular}{lclclc}
\hline Station & Hazard Score & Station & Hazard Score & Station & Hazard Score \\
\hline ABADAN & 0.426 & GHAZVIN & 0.151 & NOWSHAHR & 0.187 \\
ABADEH & 0.11 & GORGAN & 0.111 & OMIDIEYEH & 0.426 \\
ABALI & 0.168 & HAMEDANOZEH & 0.17 & OROOMIEH & 0.173 \\
AHWAZ & 0.388 & ILAM & 0.113 & PARSABADMOGHAN & 0.096 \\
ANZALI & 0.108 & IRANSHAHR & 0.426 & RAMSAR & 0.187 \\
ARAK & 0.156 & JASK & 0.256 & RASHT & 0.11 \\
ARDEBIL & 0.13 & JOLFA & 0.121 & SABZEWAR & 0.176 \\
BABOLSAR & 0.148 & KARAJ & 0.11 & SAGHEZ & 0.118 \\
BAM & 0.371 & KASHAN & 0.239 & SANANDAJ & 0.135 \\
BANDAR ABBAS & 0.426 & KASHMAR & 0.231 & SEMNAAN & 0.201 \\
BANDAR LENGEH & 0.426 & KERMAN & 0.201 & SHAHREKORD & 0.135 \\
BIRJAND & 0.193 & KERMANSHAH & 0.201 & SHAHROOD & 0.148 \\
BOJNOURD & 0.118 & KHALKHAL & 0.13 & SHIRAZ & 0.193 \\
BUSHEHR & 0.505 & KHORAMABAD & 0.193 & TABAS & 0.089 \\
CHABAHAR & 0.426 & KHOY & 0.135 & TABRIZ & 0.135 \\
DEZFUL & 0.426 & KOOHRANG & 0.13 & TEHRANMEHRABAD & 0.184 \\
DOUSHANTAPEH & 0.193 & MAHABAD & 0.118 & TORBATHEYDARIEH & 0.078 \\
ESFAHAN & 0.193 & MAKO & 0.13 & YAZD & 0.201 \\
FASSA & 0.193 & MARAGHEH & 0.118 & ZABOL & 0.239 \\
GHARAKHIL & 0.151 & MASHHAD & 0.118 & ZAHEDAN & 0.231 \\
& & & & ZANJAN & 0.118
\end{tabular}

north. In the south and central parts, the streets and buildings should be designed in accordance with hot and sultry conditions. The northern cities require sheltered and narrow streets to protect the pedestrians from cold weather. But in the south the streets should be wide enough to cope with prolonged hot summers. The buildings should be designed in a way to block the penetration of excessive solar radiation inside. In the north the buildings should allow the solar radiation inside via large windows and solar oriented facades. The designing process should proceed in a way to prevent fossil energy use and get more benefit from renewable solar and wind energy. In this way air pollution will decrease and global warming may cease. Most of the cities require a high capacity drainage mechanism such as underground drainage systems to prevent the sudden torrential rains and floods.

\section{Conclusions}

We studied the spatial distribution of climate hazards over Iran in relation to the planning and designing of sustainable urban environments; The results show that the climate hazards and vulnerability are present all over the country but with different degrees. The degree of climate risk decreases from south toward the northern parts. The most hazardous part of the country is the southern part, where the hot and humid summers cause harsh living conditions. In the northern parts the main climate hazard is the cold and icy conditions of the winter season. The extreme rains are harmful in the south but not in the north. The spatial variability of the climate hazards indicates that different urban structures should be planned for the different parts of the country. In order to plan and manage a sustainable city, the planners and designers should provide summer comfort in the south and winter comfort in the northern parts of the country.

Edited by: M. Dolinar

Reviewed by: M. Farajzadeh and another anonymous referee

SC $\mid$ nat $\$ \begin{aligned} & \text { The publication of this article is sponsored } \\ & \text { by the Swiss Academy of Sciences. }\end{aligned}$

\section{References}

Alijani, B.: Variations of $500 \mathrm{hPa}$ flow patterns over Iran and surrounding areas and their relationship with the climate of Iran, Theor. Appl. Climatol., 72, 41-54, 2002.

Alijani, B., O'Brien, J., and Yarnal, B.: Spatial analysis of precipitation intensity and concentration in Iran, Theor. Appl. Climatol., 94, 107-124, 2008.

Bärring, L. and Persson, G.: Influence of climate change on natural hazards in Europe. Natural and technological hazards andrisks affecting the spatial development of European regions, Geol. S Finl., 42, 93-107, 2006.

Bell, J., Sloan, L. C., and Snyder, M. A.: Regional Changes in Extreme Climatic Events: A Future Climate Scenario, J. Climate, 17, 81-87, 2004. 
Díaz, J., García-Herrera, R., Trigo, R. M., Linares, C., Valente, M. A., De Miguel, J. M., Frich, E., Alexander, P. L. V., Della-Marta, P., Gleason, B., Haylock, M., Klein Tank, A. M. G., and Peterson, T.: Observed coherent changes in climatic extremes during the second half of the twentieth century, Clim. Res., 19, 193-212, 2006.

Frich, P., Alexander, L. V., Della-Marta, P., Gleason, B., Haylock, M., Klein Tank, A. M. G., and Peterson, T.: Observed coherent changes in climatic extremes during the second half of the twentieth century, Clim. Res., 19, 193-212, 2002.

Givoni, B.: Climate Considerations in Building and Urban Design, Van Nostrand Reinhold, New York, 1998.

Grunthal, G., Thieken, A. H., Schwarz, J., Radtke, K. S., Smolka, A., and Merz, B.: Comparative Risk Assessments for the City of Cologne - Storms, Floods, Earthquakes, Nat. Hazards, 38, 2144, doi:10.1007/s11069-005-8598-0, 2006.

Gwilliam, J., Fedeski, M., Lindley, S., Theuray, N., and Handley, J.: Methods for assessing risk from climate hazards in urban areas. Proceedings of the Institution of Civil Engineers, Municipal Engineer, 159, 245-255, 2006.

Hayhoe, K., Kalkstein, L., Moser, S., and Miller, N.: Rising Heat and Risks to Human Health: Technical Appendix, Union of Concerned Scientists Publications, Cambridge, MA, USA, 2004.

Haylock, M. and Nicholis, N.: Trends in extreme rainfall indices for an updated high quality data set for Australia, 1910-1998, Int. J. Climatol., 20, 1533-1541, 2000.

IPCC: Assessment Report 4, Climate Change 2007: Synthesis Report, 2007.

Kary, S.: Spatial and Temporal analysis of heat waves and cold spells in Tehran urban area, M.S. Thesis, Tarbiat Moalem University, Tehran, Iran, 2010.

Kaviani, M. R., Gayour, H. A., and Payandeh, N.: Evaluating the effective temperature over Iran, Quarterly Journal of Geographical Researches, 80, 13540-13549, 2004.
Matzarakis, A. and Mayer, H.: Atmospheric conditions and human thermal comfort in urban areas, Proceedings of 11th Seminar on Environmental Protection "Environment and Health", 20-23 November 2000, Thessaloniki, Greece, 155-166, 2000.

Morgan, M. H.: Vitruvius, The Ten Books On Architecture, Dover Publications, New York, 1960.

Olgyay, V.: Design with Climate, Princeton University Press, New Jersey, 1963.

Oke, T. R.: Boundary layer climates, 2nd Edn., Routledge, New York, 1987.

Rahimzadeh, F., Asgari, A., and Fattahi, E.: Variability of extreme temperature and precipitation in Iran during recent decades, Int. J. Climatol., 29, 329-343, 2009.

Rasooli, A. A.: Spatial modeling the wind cooling in the northwest of Iran, Quarterly Journal of Geographical Researches, 80, 13559-13579, 2004.

Saati, T.: The Analytic Hierarchy Process: Planning, Priority Setting, Resource Allocation, ISBN 0-07-054371-2, McGraw-Hill, New York, 1980.

Steadman, R. G.: The assessment of sultriness. Part I: A temperature-humidity index based on human physiology and clothing science, J. Appl. Meteorol., 18, 861-873, 1979.

Tagavi, F. and Mohammadi, H.: Studying the return period of climatic extreme events in order to understand their environmental effects, J. Environ. Stud., 43, 11-20, 2007.

Zaboli, S.: Climatic potentials of kerman province of Iran for tourism activities, M.A. Thesis, Tabarestan University, Chalus, Iran, 2010.

Zhang, X., Aguilar, E., Sensoy, S., Melkonyan, H., Tagiyeva, U., Ahmed, N., Kutaladze, N., Rahimzadeh, F., Taghipour, A., Hantosh, T. H., Albert, P., Semawi, M., Karam Ali, M., Halal, M., AlShabibi, S., Al-Oulan, Z., Zatari, T., Al Dean Khelet, I., Hamoud, S., Sagir, R., Demircan, M., Eken, M., Adiguzel, M., Alexander, L., Peterson, T. C., and Wallis, T.: Trends in the Middle East climate extreme indices from 1950 to 2003, J. Geophys. Res., 110, D22104, doi:10.1029/2005JD006181, 2005. 